DOI: 10.12731/2658-6649-2019-11-5-2-28-33

УДК 616.831-005.1-005.4-005.7-06-098

\title{
ЧАСТОТА ВСТРЕЧАЕМОСТИ СЕРДЕЧНОЙ НЕДОСТАТОЧНОСТИ И АНТИТРОМБОТИЧЕСКАЯ ТЕРАПИЯ У БОЛЬНЫХ С ФИБРИЛЛЯЦИЕЙ ПРЕДСЕРДИЙПО ДАННЫМ ГОСПИТАЛЬНОГО РЕГИСТРА КРАФ
}

Гоголачвили Н.Г., Тучков А.А., Яскевич Р.А.

Изучена частота встречаемости сердечной недостаточности и системных эмболий, а также адекватность антитромботической терапии (АTT) у 664 пачиентов с неклапанной фибрилляцией предсердий (ФП), по данным госпитального регистра КРАФ. Распространенность СН по данным регистра КРАФ составила 52,7\% (57,2\% мужчин и 49,2\% уженшин $(p=0,03))$. Частота встречаемости СН у паџиентов с ФП увеличивалась с возрастом. Адекватную терапию ОАК на догоспитальном этапе принимали 39, 1\% пациентов с ФП и СН.

Ключевые слова: фибриллячия предсердий; сердечная недостаточность; антитромботическая терапия.

\section{CARDIAC INSUFFICIENCY FREQUENCY AND ANTI-THROMBOTIC THERAPY IN PATIENTS WITH ATRIAL FIBRILLATION ACCORDING TO THE INFORMATION PROVIDED BY THE HOSPITAL REGISTR KRAF}

Gogolashvili N.G., Tuchkov A.A., Yaskevich R.A.

The frequency of occurrence of heart failure and systemic emboli was studied, as well as the adequacy of antithrombotic therapy (ATT) in 664 patients with non-valvular atrial fibrillation (AF), according to the KRAF hospital register. The prevalence of $H F$ according to the KRAF registry was $52.7 \%(57.2 \%$ of men and $49.2 \%$ of women $(p=0.03))$. The frequency of occurrence of HF in 
patients with AF increased with age. Adequate treatment of KLA at the prehospital stage was taken by $39.1 \%$ of patients with $A F$ and $H F$.

Keywords: atrial fibrillation; heart failure; antithrombotic therapy.

\section{Введение}

Фибрилляция предсердий (ФП) является наиболее распространенным устойчивым нарушением сердечного ритма [1 c. 403]. Данная аритмия ассоциирована с двукратным увеличением смертности в связи с риском развития системных тромбоэмболий, независимо от наличия других факторов риска $[3$, c. 13,4, с. 3,5, c. 43,7, c. 7$]$, а также сердечной недостаточностью $(\mathrm{CH})[6$, c. 967]. СН и ФП часто сосуществуют [2, с. 391]. Показано, среди пациентов с впервые возникшей ФП в сочетании с $\mathrm{CH}$, отмечался высокий риск летальности в течение одного года по сравнению с пациентами без ФП [7, с. 126].

\section{Цель исследования}

Изучить частоту встречаемости СН у больных с неклапанной ФП по данным госпитального регистра КРАФ и оценить антитромботическую терапию (АТТ) у больных с ФП и СН.

\section{Материалы и методы}

Обследовано 664 пациента с ФП входящих в госпитальный регистр НИИ медицинских проблем Севера КРАФ. Диагноз ФП устанавливался в соответствие с действующими рекомендациями. Оценка риска тромбоэмболических осложнений проводилась по шкале $\mathrm{CHA}_{2} \mathrm{DS}_{2}$-VASc, риска кровотечений по шкале HAS-BLED.

\section{Результаты}

Распространенность СН по данным регистра КРАФ составила 52,7\% $(57,2 \%$ мужчин и 49,2\% женщин $(\mathbf{p}=\mathbf{0 , 0 3})$ ). Была проанализирована частота распространенности СН в зависимости от формы ФП. При пароксизмальной форме ФП частота встречаемости СН составила 49,4\% (56,5\% мужчин и 44,6\% женщин), при персистирующей - 33,3\% (26,8\% мужчин и $36,2 \%$ женщин), при перманентной - 65,1\% (67,4\% мужчин и $62,6 \%$ женщин). Нами была проанализирована частота встречаемости СН у пациентов с ФП в зависимости от возраста: $52,6 \%$ (56,6\% мужчин и 45,5\% женщин) у пациентов моложе 65 лет, 50\% (53,7\% мужчин и 47,1\% женщин) у пациентов в возрасте 65-74 года и 55,3\% (64,4\% мужчин и 52,3\% женщин) у пациентов 75 лет и старше. 
Согласно рекомендациям, при отсутствии противопоказаний АТТ должна назначаться всем пациентам с ФП и СН, независимо от наличия иных факторов риска тромбоэмболических осложнений по шкале $\mathrm{CHA}_{2} \mathrm{DS}_{2}$ VASc. В связи с этим, нами была проанализирована ATT на госпитальном этапе у пациентов с ФП и СН. Средний балл по шкале $\mathrm{CHA}_{2} \mathrm{DS}_{2}$-VASc у больных с СН составил 4,5 1,6, у мужчин $-3,6 \pm 1,4$, у женщин $-5,3 \pm 1,4$ балла. Установлено, что адекватную терапию оральными антикоагулянтами (ОАК) получали $39,1 \%$ пациентов с ФП и СН - 42,2\% мужчин и $36,4 \%$ женщин. Из них, 21,1\% принимали варфарин (25,9\% мужчин и $16,8 \%$ женщин $(\mathrm{p}=0,03)), 18 \%$ принимали новые оральные антикоагулянты (НОАК) (16,3\% мужчин и 19,6\% женщин). На долю дезагрегантов приходится большее число назначений - 57,4\% (54,2\% мужчин и $60,3 \%$ женщин). Абсолютно никакой АТТ не получали $3,5 \%$ пациентов (3,6\% мужчин и $3,3 \%$ женщин). Стоит отметить, что среди пациентов, принимающих дезагреганты, 15,4\% имели высокий риск кровотечений: 13,3\% мужчин и $17,1 \%$ женщин. Среди пациентов, не принимающих АТТ, высокий риск кровотечений имели $33,3 \%$ человек: $66,6 \%$ женщин. В целом, средний балл по шкале HAS - BLED у больных с CH составил $1,9 \pm 0,7$, у мужчин - $1,7 \pm 0,8$, у женщин $-2,1 \pm 0,7$ балла.

\section{Заключение}

Распространенность СН по данным регистра КРАФ составила 52,7\% $(57,2 \%$ мужчин и $49,2 \%$ у женщин $(\mathrm{p}=0,03))$. Частота встречаемости СН у пациентов с ФП увеличивалась с возрастом. Адекватную терапию ОАК на догоспитальном этапе принимали $39,1 \%$ пациентов с ФП и СН.

\section{Список литература}

1. Затонская Е.В., Матюшин Г.В., Гоголашвили Н.Г. Распространенность и клиническое значение нарушений ритма сердца // Рациональная фармакотерапия в кардиологии. 2017. Т. 13. № 3. С. 403-408.

2. Затонская Е.В., Матюшин Г.В., Гоголашвили Н.Г., Новгородцева Н.Н. Связь аритмий со структурными изменениями сердца и нарушениями его функции по данным эхокардиографии у взрослого населения заполярья // $\mathrm{Pa}$ циональная фармакотерапия в кардиологии. 2016. Т. 12. № 4. С. 391-395.

3. Клеменков А.С., Фурсова Я.Е., Клеменков С.В. и др. Влияние общих пресных ванн и физических тренировок при разной длительности назначения на физическую работоспособность больных стабильной стенокардией с нарушением ритма // Фундаментальные исследования. 2006. № 3. С. 13. 
4. Разумов А.Н., Бобровницкий И.П., Колесникова И.В. и др. Влияние электромагнитных полей на тонус церебральных сосудов и артериальное давление // Вопросы курортологии, физиотерапии и лечебной физической культуры. 2006. № 2. С. 3-5.

5. Тучков А.А., Гоголашвили Н.Г., Яскевич Р.А. Оценка динамики антитромботической терапии у пациентов с фибрилляцией предсердий в течение 2015-2017 гг. По данным регистра клиники научно-исследовательского института медицинских проблем севера г. Красноярска // Рациональная фармакотерапия в кардиологии. 2019. Т. 15. № 1. С. 43-48.

6. Prabhu S., Voskoboinik A., Kaye D.M., Kistler P.M. Atrial Fibrillation and Heart Failure - Cause or Effect? // Heart, Lung and Circulation. 2017. Vol. 26(9), pp. 967-974.

7. Thihalolipavan S., Morin D.P. (2015). Atrial Fibrillation and Heart Failure: Update 2015 // Progress in Cardiovascular Diseases. 2015. Vol.58 (2), pp. 126-135.

\section{References}

1. Zatonskaya E.V., Matyushin G.V., Gogolashvili N.G. Rasprostranennost' i klinicheskoe znachenie narushenij ritma serdca [The prevalence and clinical significance of cardiac arrhythmias] // Racional'naya farmakoterapiya v kardiologii [Rational pharmacotherapy in cardiology]. 2017. T. 13. № 3. S. 403-408.

2. Zatonskaya E.V., Matyushin G.V., Gogolashvili N.G., Novgorodceva N.N. Svyaz' aritmij so strukturnymi izmeneniyami serdca i narusheniyami ego funkcii po dannym ekhokardiografii u vzroslogo naseleniya zapolyar'ya [The connection of arrhythmias with structural changes in the heart and impaired function of the heart according to echocardiography in the adult population of the Arctic // Racional'naya farmakoterapiya $\mathrm{v}$ kardiologii [Rational pharmacotherapy in cardiology]. 2016. T. 12. № 4. S. 391-395.

3. Klemenkov A.S., Fursova Ya.E., Klemenkov S.V. i dr. Vliyanie obshchih presnyh vann i fizicheskih trenirovok pri raznoj dlitel'nosti naznacheniya na fizicheskuyu rabotosposobnost' bol'nyh stabil'noj stenokardiej s narusheniem ritma [The influence of common freshwater baths and physical training for different durations of administration on the physical performance of patients with stable angina pectoris with rhythm disturbances] // Fundamental'nye issledovaniya [Fundamental Studies]. 2006. № 3. S. 13.

4. Razumov A.N., Bobrovnickij I.P., Kolesnikova I.V. i dr. Vliyanie elektromagnitnyh polej na tonus cerebral'nyh sosudov i arterial'noe davlenie [The influence of electromagnetic fields on the tone of cerebral vessels and blood pressure] // 
Voprosy kurortologii, fizioterapii i lechebnoj fizicheskoj kul'tury [Questions of balneology, physiotherapy and physical culture]. 2006. № 2. S. 3-5.

5. Tuchkov A.A., Gogolashvili N.G., Yaskevich R.A. Ocenka dinamiki antitromboticheskoj terapii u pacientov s fibrillyaciej predserdij v techenie 2015-2017 gg. Po dannym registra kliniki nauchno-issledovatel'skogo instituta medicinskih problem severa g. Krasnoyarska [Evaluation of the dynamics of antithrombotic therapy in patients with atrial fibrillation during 2015-2017. According to the register of the clinic of the Research Institute of Medical Problems of the North of Krasnoyarsk] // Racional'naya farmakoterapiya $v$ kardiologii [Rational Pharmacotherapy in Cardiology]. 2019. T. 15. № 1. S. 43-48.

6. Prabhu S., Voskoboinik A., Kaye D.M., Kistler P.M. Atrial Fibrillation and Heart Failure-Cause or Effect? // Heart, Lung and Circulation. 2017. Vol. 26(9), pp. 967-974.

7. Thihalolipavan S., Morin D.P. Atrial Fibrillation and Heart Failure: Update 2015 // Progress in Cardiovascular Diseases. 2015. Vol.58 (2), pp. 126-135.

\section{ДАННЫЕ ОБ АВТОРАХ}

Гоголашвили Николай Гамлетович, д.м.н., главный научный сотрудник, профессор кафедры кардиологии и функциональной диагностики ИПО

Федеральное государственное бюджетное научное учреждение "Научно-исследовательский институт медицинских проблем Севера»; ГБОУ ВПО «КрасГМУ им. проф. Ф.В. Войно-Ясенеикого» MЗ $Р \Phi$

ул. Партизана Железняка, 32, г. Красноярск, 660022, Российская Федерачия; ул. Партизана Железняка, 1а, г. Красноярск, 660022, Российская Федерачия

gng1963@mail.ru

Тучков Александр Александрович, младший научный сотрудник

Федеральное государственное бюджетное научное учреждение «Научно-исследовательский институт медичинских проблем Севера»

ул. Партизана Железняка, 32, г. Красноярск, 660022, Российская Федераиия

aatuchkov@mail.ru

Яскевич Роман Анатольевич, к.м.н., доцент, ведущий научный сотрудник, доцент кафедры пропедевтики внутренних болезней и терапии 
Федеральное государственное бюджетное научное учреждение «Научно-исследовательский институт медицинских проблем Севера»; ГБОУ ВПО «КрасГМУ им. проф. Ф.В. Войно-Ясенечкого» MЗ $P \Phi$

ул. Партизана Железняка, 32, г. Красноярск, 660022, Российская Федерация; ул. Партизана Железняка, 1а, г. Красноярск, 660022, Российская Федерачия

holter-24@yandex.ru

\section{DATA ABOUT THE AUTHORS}

Gogolashvili Nikolai Gamletovich, M.D., chief researcher, professor of the department of cardiology and functional diagnostics of IPO Federal State Budgetary Scientific Institution «Scientific Research Institute of medical problems of the North»; Krasnoyarsk State Medical University named after Professor V.F. Voino-Yasenetzkiy

3g, Partizan Zheleznyaka str., Krasnoyarsk, 660022, Russian Federation; 1a, P. Zheleznyaka St., Krasnoyarsk, 660022, Russian Federation gng1963@mail.ru

Tuchkov Alexander Aleksandrovich, junior researcher

Federal State Budgetary Scientific Institution «Scientific Research Institute of medical problems of the North»

3g, Partizan Zheleznyaka str., Krasnoyarsk, 660022, Russian Federation aatuchkov@mail.ru

Yaskevich Roman Anatolyevich, candidate of medical sciences, associate professor, leading researcher, associate professor at department of propedeutics of internal diseases and therapy

Federal State Budgetary Scientific Institution «Scientific Research Institute of medical problems of the North»; Krasnoyarsk State Medical University named after Professor V.F. Voino-Yasenetzkiy

3g, Partizan Zheleznyaka str., Krasnoyarsk, 660022, Russian Federation; 1a, P. Zheleznyaka St., Krasnoyarsk, 660022, Russian Federation holter-24@yandex.ru 